\title{
The role of emic understandings in theorizing im/politeness: the metapragmatics of attentiveness, empathy and anticipatory inference in Japanese and Chinese
}

\author{
Saeko Fukushima and Michael Haugh
}

\begin{abstract}
While the notion of face has continued to play a key role in many accounts of im/politeness, there has increasingly been calls for im/politeness to be theorized in its own right, drawing from the emic understandings of members in relation to im/politeness. In this paper, we make a contribution to this latter agenda by comparing emic understandings of attentiveness, and the related notions of empathy and anticipatory inference, in Japanese and Taiwanese Mandarin Chinese. Drawing from metapragmatic interviews with Japanese and Taiwanese participants from two different generations, we suggest that there are both similarities and differences in the ways in which these notions are conceptualized among speakers of Japanese and Mandarin Chinese spoken in Taiwan. It was found that while the participants evaluated these practices positively, and in some cases linked to politeness concerns, in other instances they evaluated them negatively. Intracultural variability also emerged in the course of our cross-generational-cultural comparison. We conclude that further work investigating the metapragmatics of interpersonal notions such as attentiveness, empathy and anticipatory inference is necessary if we are to better understand the moral grounds on which evaluations of im/politeness are made across different languages and cultures.
\end{abstract}

\section{Keywords}

politeness, impoliteness, metapragmatics, metalanguage, emic understandings, attentiveness

\section{Introduction}

It is now widely accepted that politeness and impoliteness arise through evaluations by participants in situated discourse or interactional contexts. A central role has thus been afforded to the understandings of participants in analyzing im/politeness (Eelen 2001; Haugh 2007c; Mills 2003; Kádár and Haugh 2013; Watts 2003). However, to treat participants' perspective as important does not simply entail the analyst identifying the evaluations of those particular participants as they arise in interaction, but also examining the assumed or tacit values that are invoked by participants in making such evaluations. To make an evaluation necessarily involves an (implicit) appeal to some kind of yardstick against which the use of particular language and the conduct more generally of self and others is judged (Haugh 2013a: 64-65). This has often been couched in terms of "norms", although Eelen (2001: 135) argues against approaches that reify such norms as pre-existing or static sets of values in a particular culture. Nevertheless, it is important to bear in mind that when evaluating something as polite, impolite and so on, participants are implicitly claiming their evaluations are not idiosyncratic, but rather are grounded in the "seen but unnoticed" sets of expectancies that constitute what Garfinkel (1967: 35-36) termed "the moral order". In other words, when evaluating something as im/polite, one is invoking, and thereby further co-constituting, moral aspects of that social action or meaning (Haugh 2013b: 56-60; Kádár and Haugh 2013: 65-73). Given the moral order itself, and thus the inherently moral nature of evaluations of im/politeness, is sustained through the way in which members are "responsive to this background" (Garfinkel 1967: 36), the question thus arises as to what constitutes the "'seen but unnoticed' expected, background features” (Garfinkel 1967: 35-36) in which such evaluations are grounded. This necessitates, in turn, a focus on emic understandings of aspects of the moral order that relate to evaluations of im/politeness (Haugh 2007b: 659, 2013a: 61-64; Kádár and Haugh 2013: 181-205). In other words, we need to analyze the understandings of those members who claim an insider perspective on these background, and more often than not, unnoticed expectancies.

In much of the work to date, researchers have appealed to face as underpinning evaluations of im/politeness (e.g., Brown and Levinson 1987; Bousfield 2008; Locher and Watts 2005; Spencer-Oatey 2005). However, understandings of face as a kind of publically endorsed social image, including interactional claims for approval from others (i.e. positive face) or freedom from imposition (i.e. negative face), have been found severely wanting in analyses of im/politeness in many languages and cultures, including in Chinese and Japanese (e.g., Haugh 2004, 2005; Ide 1989; Mao 1994; Matsumoto 1988; Pan and Kádár 2011). Intachakra (2012) has thus recently renewed calls for a search for alternative metaphors 
for analyzing and theorizing im/politeness that draw from other cultural perspectives. Intachakra (2012: 632) argues that we should "treat politeness as an interface where indigenous politeness concepts are brought in from as wide-ranging languages (including English) as possible, in order to establish a concoction of modalities of expression shared by those (if not all) languages". However, tapping into emic understandings vis-à-vis im/politeness inevitably involves some form of metapragmatic analysis, given we are moving into an examination of reflexive awareness on the part of ordinary or lay observers about the ways in which they use language to interact and communicate with others (Haugh 2010a; Kádár and Haugh 2013: 184). Metapragmatic analysis of im/politeness involves the study of linguistic evidence that language users are aware of (potential) evaluations of im/politeness1 including (1) the metalanguage of im/politeness (i.e. metalinguistic awareness), (2) metapragmatic commentary (i.e. metacommunicative awareness), (3) social discourse(s) on im/politeness (i.e. metadiscursive awareness), and (4) pragmatic markers that are interpretable as displaying metapragmatic awareness on the part of users (i.e. metacognitive awareness) (Kádár and Haugh 2013: 186-187). It thus goes beyond the treatment of metapragmatics of politeness1 as simply encompassing instances of talk about politeness as a concept (see, e.g., Eelen 2001; Terkourafi 2011).

One of the challenges facing a metapragmatic approach to im/politeness, then, is how to deal with differences in lay or first-order conceptualizations of im/politeness (or what is commonly termed $\mathrm{im}$ /politeness1), across languages and cultures at various levels of social groupings. In this exploratory paper, we take up this theme in relation to emic conceptualizations of "attentiveness" (kikubari), "empathy" (omoiyari) and "anticipatory inference" (sasshi) in Japanese and Mandarin Chinese spoken in Taiwan, and how the values inherent to these notions can scaffold evaluations of (im)politeness1. We propose that the emic understandings of such notions underpin the "seen but unnoticed" sets of expectations that ground evaluations of (im)politeness1 by participants, at least in some instances. These three notions are interlinked, that is, empathy and anticipatory inference are needed in order to demonstrate attentiveness. A demonstrator of attentiveness may empathize with a potential beneficiary and demonstrate attentiveness as a result (Fukushima 2013a: 26); and a definite prerequisite for attentiveness to arise is inference by a potential demonstrator of attentiveness (Fukushima 2013a: 28) (see a detailed explanation of these concepts in section 2). We undertake a cross-cultural and cross-generational comparison of emic understandings of these notions among speakers of Japanese and Taiwanese speakers of Mandarin Chinese, using the metapragmatic interview data (see section 3). Although notions such as attentiveness, empathy and anticipatory inference have been claimed to form an important cornerstone of im/politeness 1 from an emic perspective in Japanese (see, e.g., Clancy 1986; Fukushima 2000, 2004, 2009, 2011, 2013b; Ishii 1984; Marui et al. 1996; Miike 2003; Miyake 2011; Travis 1998), there has been little systematic investigation of analogous notions in Chinese, and indeed very few studies undertaking comparisons of politeness in Japanese and Chinese. Thus, we not only address the considerable gap in relation to studies investigating cross-generational differences in understandings of im/politeness1 (although see Fukushima 2011; 2013b), we further suggest that comparing emic understandings of analogous notions in Japanese and Chinese is also arguably useful in that it allows us to better characterize specific nuances that might not appear salient in a straightforward comparison with related notions in English, for instance.

In the next section, we introduce the emic notions of attentiveness, empathy and anticipatory inference that arguably frame evaluations of im/politeness on some occasions in Japanese and Taiwanese Mandarin Chinese. We subsequently describe the procedure and the participants of our interview, and then analyze how their responses indicate both possible similarities and differences in the ways these notions are conceptualized among lay speakers of Japanese and Mandarin Chinese spoken in Taiwan. We then briefly consider the implications of this study for theorizing im/politeness more broadly.

\section{2. “Im/politeness” in Japanese and Chinese: attentiveness, empathy and anticipatory inference}

Politeness is often broadly defined in terms of showing "consideration" or "concern" for others. Sifianou (1992: 86), for instance, after reviewing various definitions of politeness, concludes that it involves "the set of social values which instructs interactants to consider each other by satisfying shared expectations" (emphasis added), while Watts (2003: 28) broadly defines politeness (more specifically, politic behavior) as "mutually shared forms of consideration for others" (emphasis added). The notion of "consideration", though, despite its obvious importance to politeness research, has rarely been the object of any detailed 
analysis. According to Travis (1997: 150), consideration in English essentially involves avoiding actions that could show one has not thought about that person's circumstances or situation, and which might, therefore, be perceived as hurtful. However, we would argue that this is an overly narrow construal of this notion, and instead propose that there are two ways in which consideration can manifest itself. First, consideration can arise through paying attention to the other party's circumstances, but doing or saying nothing to the other party as a result (cf. Travis 1997: 150). For example, consideration can be indicated through refraining from commenting on a contentious claim or action, which might in some situations "hurt" that person's feelings, or by simply leaving the other party alone. Second, it can arise through paying attention to the other party, but in this case tuning one's feelings more strongly in line with those of the other party, and acting accordingly. This form of consideration is termed "standing in the place of the other party" (Uchida and Kitayama 2001), or "feeling what others are feeling” (Lebra 1976). The latter form of consideration can thus be labelled as a form of empathy, which may consequently lead to a demonstration of attentiveness, that is, doing something for the other party (Fukushima 2004, 2011).

The importance placed on being considerate among lay observers is thus more or less reflective of the importance placed by (at least some) politeness researchers on the avoidance of imposition as a key form of politeness, namely, so-called negative politeness (Brown and Levinson 1987). However, what counts as "consideration", arguably carries different nuances depending on one's language and cultural background. In this paper, we aim to clarify these different nuances among speakers of Japanese and Taiwanese Mandarin Chinese. In particular, we propose that a better understanding of what counts as “consideration” vis-à-vis im/politeness can be gained through exploring the value placed on attentiveness, empathy and anticipatory inference in particular situated contexts among speakers of those languages. ${ }^{1}$ In this way, we are also proposing that we move beyond a narrow focus on "avoiding imposition" in theorizing im/politeness.

The notion of attentiveness is represented through two closely related terms in Japanese, namely, kikubari (気配り) and kizukai (気遣い). Both terms draw from the notion of ki (気), which is variously translated as "spirit; mind; heart”, "mind; intention; will”, "feelings; mood”, "nature; disposition”, “care; precaution; attention" or "air; atmosphere”(Kenkyusha's New Japanese-English Dictionary, $5^{\text {th }}$ edition, 2003). Here $k i$ is understood in the sense of a "mood", "attention" or "atmosphere" felt through the presence or influence of others (Hamano 1987: 109). Indeed, $k i$ is seen as attention toward others, and it can be said that our personality is evaluated by the way we pay attention to others (Hamano 1987: 106). In the case of kikubari, $k i$, the attention to the mood, feelings or needs of others, is literally "allocated" or "distributed" (kubaru), while in the case of kizukai, ki is literally "worked" (tsukau), in the sense of kokoro o hatarakaseru (Kojien $6^{\text {th }}$ edition, 2008). Marui et al. (1996: 395) treat kizukai as a form of “reading others' needs”, while Lebra (2004: 44) suggests it can be glossed as “alertness and caring attention to other's needs or feelings".

Fukushima (2004, 2009: 504; 2011: 550; 2013b: 279), however, defines attentiveness more specifically as “a demonstrator's pre-emptive response to a beneficiary's verbal or non-verbal cues or situations surrounding a beneficiary and a demonstrator, which takes the form of offering”. On this view, to be "attentive" is for the demonstrator to do something for a beneficiary without or before being asked, having inferred the likely needs or wants of a potential beneficiary (Fukushima 2011: 550). ${ }^{2}$ Attentiveness thus means paying attention to the others by the work of $k i$, that is, reading the atmosphere in a situation and anticipating or inferring the other party's feelings, needs and wants. A pre-emptive response, which can take the form of offering, may consequently arise. For instance, one can offer to lend someone a pen by saying "Shall I lend you my pen?" (in which case attentiveness is manifested verbally), or by just handing a pen to that person (and so attentiveness is manifested behaviourally), or by handing a pen, saying "You can use this" (in which case attentiveness is manifested both verbally and behaviourally) to someone who has said "I forgot my pen" (verbal cue), who is visibly searching for a pen in a bag (non-verbal cue), or who otherwise indicates they don't have a pen when attending a lecture (situation) (Fukushima 2009: 504-505). Pre-emptive offers, however, do not necessarily mean offering material things, such as a pen, but may also

\footnotetext{
${ }^{1}$ The extent to which this expanded notion of consideration plays a role in evaluations of im/politeness among speakers of other languages clearly remains a topic for further research, although see Fukushima (2004) for an examination of attentiveness among British speakers of English and Swiss speakers of German, Fukushima (2009) for that among British speakers of English, and Fukushima (2011; 2013b) for that among American speakers of English.

2 See Fukushima (2013a: 21-23) for further discussion of the process of demonstration and evaluation of attentiveness.
} 
include non-material things, such as opening the window when it is hot, helping someone on seeing them experience some form of trouble (e.g., helping strangers in the street [see Sifianou \& Tzanne 2010]), or making suggestions (e.g., “Shall I come to pick you up?”), before or without being asked, by taking the verbal/non-verbal cues and the situation into account. Instances of non-material offers may be either tangible actions, such as opening the window, or intangible ones, such as making suggestions. However, there are also cases in which attention is paid to the feelings, needs or wants of others, but pre-emptive offers are withheld, in light of the situation or the state of the other party. In the latter case, of course, no demonstrable manifestation of attentiveness can be observed. In this paper though the term "attentiveness" is used primarily to instances where it is demonstrated through pre-emptive offers that are made as a result of anticipating or inferring the feelings, needs or wants of another party, unless otherwise specified, as it is this sense of attentiveness which is arguably the most relevant to evaluations of im/politeness.

There are, according to Fukushima (2011: 550), two main orientations of attentiveness: genuine attentiveness and reflexive attentiveness. Genuine attentiveness involves displaying concern for the well-being of a beneficiary through making a pre-emptive offer, which can, in some instances, be evaluated as "polite", while in other instances may be evaluated as "meddling”. Reflexive attentiveness, on the other hand, concerns demonstrations of attentiveness for the sake of demonstrator him/herself, that is, to enhance his or her reputation as someone who is "kind" (yasashii or shinsetsu) or "attentive" (kigakiku) (Fukushima 2011: 550), or as a ploy to receive attentiveness from others in the future, and so on. ${ }^{3}$ Notably, to be evaluated as kind or attentive intersects with the broader field of politeness1-evaluators in Japanese (Haugh 2004: 95; Pizziconi 2007: 219), although the distinctions between the two is open to further exploration. ${ }^{4}$ Even when reflexive attentiveness is demonstrated for the benefit of a demonstrator, it may also help a beneficiary (Fukushima 2011: 550).

In order to demonstrate attentiveness, however, a specific form of empathy, namely, where the demonstrator displays "the ability and willingness to feel what others are feeling” (Lebra 1976: 38) is also required. In Japanese, this form of empathy is represented through the notion of omoiyari. The term omoiyari (思い遣り), which is literally to “think/consider” (omou) and “do” (yaru), can be roughly glossed as an attitudinal stance encompassing concern for the feelings of others. Lebra (1976: 38) defines omoiyari as "the ability and willingness to feel what others are feeling, to vicariously experience the pleasure or pain that they are undergoing, and to help them satisfy their wishes", while Hara (2006: 27) translates omoiyari as "altruistic sensitivity" and claims that omoiyari literally means sending one's altruistic feelings to others. Travis (1998: 55) defines omoiyari more specifically as encompassing a kind of "intuitive understanding of the unexpressed feelings, desires and thoughts of others, and doing something for them on the basis of this understanding”, while Wierzbicka (1997: 275) characterizes omoiyari as "an ability to 'read other people's minds' and a willingness to respond to other people's unspoken feelings, wants, and needs". In both the latter cases, omoiyari is treated as virtually synonymous with attentiveness. Our position, however, is that omoiyari (empathy) encompasses an attitudinal stance, while attentiveness includes displays of this attitude through pre-emptive offers, or alternatively through choosing to avoid certain actions or leaving others alone. Thus, while for some researchers, attentiveness and empathy mean the same thing, we argue that it is not prudent to conflate these potentially distinct notions when attempting an exploratory analysis of emic understandings of them. ${ }^{5}$

\footnotetext{
3 The extent to which attentiveness overlaps with Spencer-Oatey’s (2000, 2002) notion of "equity rights”, which refers to the fundamental belief that one is entitled to personal consideration from others (our emphasis), such that one is treated fairly and not unduly imposed upon or unfairly ordered about, remains a somewhat open question at this point. One notable difference is that attentiveness includes pre-emptive actions demonstrated after thinking about the needs or feelings of others.

${ }^{4}$ While both involve enhancement of the person's reputation, one point of possible difference is that the former concepts (i.e., yasashii, shinsetsu) are more affectively loaded, while the latter (i.e., kigakiku) is more like an ability, that is, "one can make a quick judgement, according to the situation”, (Kojien, $6^{\text {th }}$ edition, 2008), and one can act accordingly. This view of kigakiku as an ability matches Hamano’s (1987: 106) contention, namely, that our personality can be evaluated by the way we pay attention to others.

${ }^{5}$ It is worth noting that the notion of "empathy" represented through the term omoiyari differs subtly from the notion of empathy as it is generally understood in English. The latter is generally defined as "resonating” the feelings of others by "demonstrating an understanding of another person's situation and/or feelings and communicating that understanding back to the person so that they feel understood" (Pudlinski 2005: 267; cf. Gladkova 2010: 273). One possible difference is that empathy in English places greater emphasis on understanding another person's feelings or situation, rather than vicariously feeling them oneself, as is the case for omoiyari. It is thus important to bear in mind that while we use "empathy" in this paper as a translation of omoiyari,
} 
Yet another underlying requirement for demonstrating attentiveness is the practice of a particular form of inference, where the demonstrator draws from verbal and/or non-verbal cues to figure out what the beneficiary may want or need at that moment. In Japanese, this form of inference is described through the notion of sasshi (察し), which is glossed as "sharp guess-work” by Ishii (1994: 50). Yamada (1997: 37) goes further in defining sasshi as "the process of anticipatory guesswork required to fill out what each other is meaning in communication", and so constitutes "a strategy where participants try to understand as much as possible from the little that is said by the other". We thus gloss sasshi as a form of anticipatory inference in order to demarcate its scope as being narrower than the broader notion of inference in pragmatics, which refers to a whole range of different types of logical and sociocognitive process by which participants figure out what is meant (cf. Haugh 2013c).

While the notions of attentiveness, empathy, and anticipatory inference are often claimed to be key notions in Japanese culture, including in the context of socializing and interacting with children (Clancy 1986; Burdelski 2010; Burdelski and Mitsuhashi 2010; Takada 2013), business etiquette training (Dunn 2013), and intercultural communication (Ishii 1984; Okabe 1993; Yamada 1997), little has been said about close equivalents in Chinese. The nearest analogous notions in Chinese to attentiveness, empathy, and anticipatory inference appear to be zhōudào, tìtiē, and juéchá, respectively. Zhōudào (周到) can be roughly translated as dealing with or considering things thoroughly, although it does not imply attention to "feelings" so much as attending to the details of a situation, leading to a participant (sometimes) acting upon those "thoughts" about the overall situation, while tittie (體貼) can be glossed broadly as thorough consideration of the other's mood or showing care by standing in someone else's shoes, and so implies that participants are attending to the (sometimes intimate) feelings of others. Finally, juéchá (覺察) can be interpreted as sensing or recognizing through observing others. ${ }^{6}$ There has been little work to date on these notions and their relationship vis-à-vis evaluations of im/politeness in Chinese in contrast to Japanese, although this is not to say they are not salient concepts in Chinese, or at least so we will be arguing in the sections that follow.

In the remainder of this paper, we examine in greater detail emic understandings of attentiveness, empathy and anticipatory inference in Japanese and Taiwanese Mandarin Chinese, drawing from data elicited through metapragmatic interviews. We suggest that these notions underpin evaluations of im/politeness1 in some instances, and so this study represents another tentative step forward in better understanding of emic conceptualizations of im/politeness1 among speakers of Japanese and Mandarin Chinese spoken in Taiwan (cf. Haugh 2004; Ide et al. 1992; Obana and Tomoda 1994; Pizziconi 2007).

\section{The interview: procedure and participants}

Metapragmatic interviews about attentiveness, empathy and anticipatory inference were conducted in Japanese with Japanese participants, and in Mandarin Chinese with Taiwanese participants. The participants were asked to outline their understanding of the notions of anticipatory inference, empathy and attentiveness, and to describe instances where they have either undertaken such behavior or observed it in their interactions with others. All the interviews were audio-recorded and transcribed. The interviewer was the same person for all the interviews in each language so as to reduce the influence of different ways of eliciting responses. As Haugh (2010b: 156) points out, the role of the interviewer needs to be taken firmly into account in any analysis of interviews. This is because s/he is not a 'neutral elicitor' but rather a co-constructor of the event, both in terms of the actual 'content' of the interview data, and in terms of the ways in which the interviewee and the interviewer may attempt to position themselves. A Japanese female interviewed Japanese participants, while a Taiwanese female interviewed Taiwanese participants.

40 Japanese and Taiwanese people were approached as our participants based on existing networks of the authors at two universities in Japan and Taiwan. The mean age and the age range of the participants were as follows: younger Japanese (mean age: 21.5; age range: 20-22); older Japanese (mean age: 52; age

consistent with how it has been translated in the literature to date (e.g., Lebra 1976: 38-43), omoiyari is ultimately best understood in its own terms from an emic, insider's understanding of the concept.

${ }^{6}$ Our thanks to one of the anonymous reviewers for pointing out further nuances in the semantics of these three terms. 
range: 46-60); younger Taiwanese (mean age: 22; age range 18-24); and older Taiwanese (mean age: 46; age range: $45-54){ }^{7}$

These forty participants were equally divided into the following four groups based on age and nationality: (1) 10 Japanese in their early 20s (younger Japanese, or Japanese students) (JS); (2) 10 Japanese in their late 40s through to 60 (older Japanese, or Japanese parents) (JP); (3) 10 Taiwanese in their early 20s (younger Taiwanese, or Taiwanese students) (TS); and (4) 10 Taiwanese parents in their late 40s through to late 50s (older Taiwanese, or Taiwanese parents) (TP). All the participants were female so that we could exclude, for the time being, possible gender-based influences on the understandings we elicited. The second and the fourth groups involved participants who were all approximately in the same age groups as the parents of the first and the third groups, who were mostly university students in their early twenties, but they did not have to be related as such to the students. All the participants were broadly educated to at least post-high school qualifications. The participants were confined to those who have not studied or lived abroad for longer than two months, as we assumed that overseas experience might influence their reports about the concepts investigated in this study.

\section{Analysis of emic understandings of attentiveness, empathy and anticipatory inference in Japanese and Chinese}

Different understandings in relation to attentiveness, empathy and anticipatory inference were identified through content analysis (Krippendorff 2013). It is important to bear in mind, however, that these participants' understandings (and associated stances) emerged through dialogue with the interviewer, and so should be understood as potentially designed with respect to the presumed or perceived stance of the interviewer (Potter and Hepburn 2005; Tracy and Robles 2010). In addition, the three notions were not always clearly separated in participants' accounts of them. In other words, the participants did not always clearly distinguish between the three concepts when questioned about them. For example, in responding to a question about anticipatory inference, one participant cited an example of attentiveness (e.g., a pre-emptive offer to pick up her sister at the station). Furthermore, there was some degree of intra-cultural variability in understandings even within these relatively small samples, and so a number of analytical similarities as well as differences emerged as salient both cross-culturally (i.e. between the Japanese and Taiwanese participants) (see section 4.1) and cross-generationally (i.e. between younger and older generations across both the Japanese and Taiwanese participants) (see section 4.2).

\subsection{Cross-cultural comparison}

A number of interesting similarities as well as contrasts emerged between the Japanese and Taiwanese understandings from our analysis of the interview data. One of the similarities we identified between the Japanese and Taiwanese participants was that they often evaluated the practices by which attentiveness, empathy and anticipatory inference arise positively, and, in some cases at least, explicitly linked them to politeness concerns. ${ }^{8}$ A second similarity was that the Japanese and Taiwanese participants also reported some instances where they had evaluated attentiveness and empathy negatively as "meddling". Subtle differences were found between the Japanese and Taiwanese participants, however, with respect to their negative evaluations of attentiveness and empathy. On the one hand, the Taiwanese participants emphasized that excessive or unwanted empathy and attentiveness can be perceived as "calculating" in some instances, and that the demonstration of attentiveness can also create "emotional debts", which can cause embarrassment or even feelings of guilt on the part of the beneficiary. On the other hand, the Japanese participants perceived the demonstration of attentiveness as indicating that receiving attentiveness from others in the future is a possibility. Another difference was that only the Japanese participants identified empathy and attentiveness as "making allowances for others". We will now look at the above results more

\footnotetext{
7 All the younger Japanese and 8 of the younger Taiwanese were university students majoring in English. The other two younger Taiwanese were university graduates working as a nurse and a receptionist respectively. The occupations of the older Japanese included: two academics, four librarians, one sales clerk at a university co-op, and three part-time workers at a university library. The occupations of the older Taiwanese included: eight college lecturers and high school teachers, one administrator, and one housewife.

${ }^{8}$ It is worth noting, however, that the participants do not always clearly distinguish between these three different concepts.
} 
in detail, presenting some excerpts from the interview data to further illustrate both similarities and differences in understandings of these concepts in Japanese and Mandarin Chinese spoken in Taiwan.

One important similarity to emerge was the claim that attentiveness and empathy are important for building and maintaining (positive) interpersonal relationships, and in some cases were treated as "politeness" concerns. In relation to the latter, one of the Japanese students, for instance, explicitly linked empathy with issues of "politeness", when talking about what kind of attitude she practices towards her "seniors" at university (numbers in brackets indicate approximate lengths of pauses) ('JS6' is the interviewee, while ' $\mathrm{I}$ ' is the interviewer).

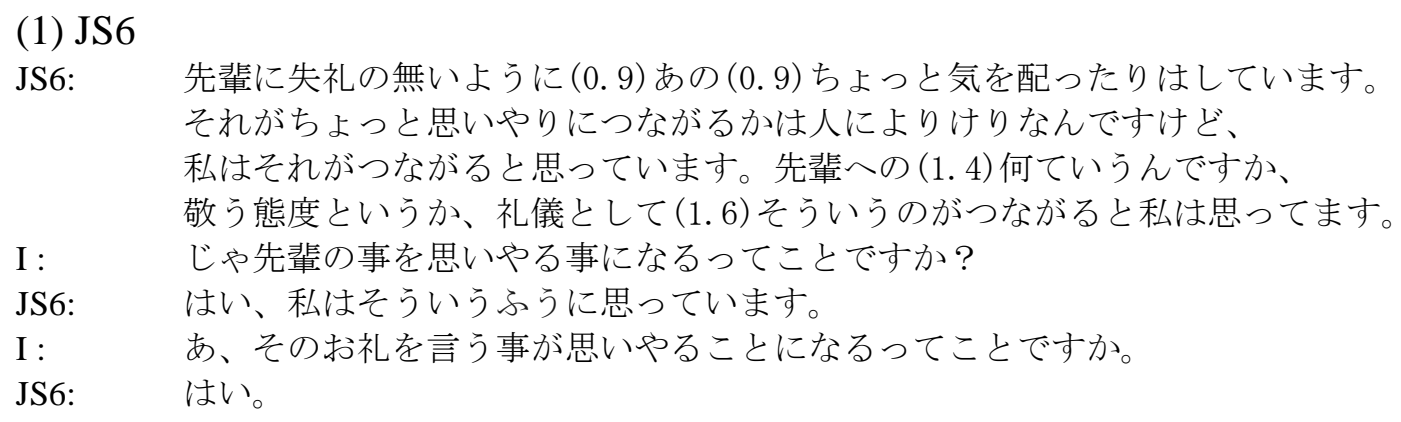

JS6: ' in order not to be rude to seniors (0.9) um (0.9) I am somewhat attentive. It depends on people whether they think being attentive would lead to empathy somehow, but I personally think it does. Towards seniors (1.4) what I can say?, a respectful (uyamau) attitude, as courtesy (reigi) (1.6) it's connected to those kinds of things I think'

I : $\quad$ 'so it's where you empathize with your seniors

JS6: 'yes I think it's like that'

I : ' 'oh, expressing gratitude (orei) leads to empathizing them?'

JS6: 'yes'

In co-constructing a joint understanding of what the student conceptualizes empathy (omoiyari) to be, the student explicitly associates it with avoiding being seen as "rude" (shitsurei), as well as linking it with "(vertically-oriented) respect" (uyamau) and "courtesy" (reigi) (Haugh 2004: 95). The student also confirms that empathy is linked with (sometimes ritualistic) "expressions of gratitude" (orei) (Ohashi 2013), following the prior talk where she mentioned such gratitude expressions (in a situation in which her colleagues and juniors do not express gratitude when the seniors bring them some sweets) (data not shown). She thus tries not to be rude to the seniors by expressing gratitude. We can see here, then, how the participant draws links between empathy notions associated with "politeness" in Japanese (such as being seen as respectful and courteous and avoiding being seen as rude), and thus how in this particular account, empathy is being explicitly oriented to as a "politeness" concern.

The Taiwanese participants also linked the practice of attentiveness with an orientation to "politeness" in some instances, as can be seen in the following excerpt from an interview with one of the Taiwanese parents.

(2) TP7

I: ～那就妳認為說, 在日常生活當中, 表現「周到」很重要嗎?

TP7：＼cjkstart嗯…倒不一定耶！因為有時候…因為人跟人相處，你不太知道他的文化或者 那個，有時候我們說禮多人不怪。

I: $\quad$ 'Do you think it is important to perform attentiveness (zhōudào) in daily life?'

TP7: 'mm....depends, because sometimes...because when people get along with each other, [when] you are not sure about his/her culture or something, sometimes we would say "courtesy costs nothing”.

The participant here explicitly characterizes attentiveness as showing "courtesy" (lī). This notion, which can also be translated as "propriety", has long been associated with discussions of "politeness" in Chinese, often in the connection with the expression limmào (lit. 'the appearance of li’) (Gu 1990; Pan and Kádár 
2011). The fact that the participant made recourse to an idiomatic saying in making this claim, namely, that being attentive is a matter of courtesy also indicates that this belief is not framed as an idiosyncratic one on her part, but one that is treated as shared across speakers of Chinese.

The second cross-cultural similarity to emerge from our analysis was the way in which these forms of anticipatory inference and empathy, as well as attentiveness, could be evaluated negatively according to both the Japanese and Taiwanese participants. One of the Japanese students, for instance, suggested that attentiveness can be seen as "meddling” or "overly excessive concern" (ossekai) when commenting on the extent to which she thinks attentiveness is important in daily interactions.

(3) JS3

\begin{tabular}{|c|c|}
\hline $\mathrm{I}:$ & えー、どの程度重要でしょうか? \\
\hline JS3: & 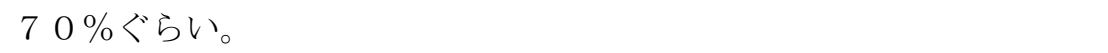 \\
\hline $\mathrm{I}$. & じゃあ、なぜでしょうか。 \\
\hline 3: & $\begin{array}{l}\text { えっと、やっ、気を配られた人はやはり、えーと嬉しいと思いますし、 } \\
\text { 気配りをしてあげる人も、悪い気はしないと思います。ただ、 } \\
\text { えっと行き過ぎるとおせっかいたなてしまうことがあるので、 } \\
\text { マイナスの } 30 \% \text { \%ずす。 }\end{array}$ \\
\hline
\end{tabular}

I: ' 'um, to what extent is it [attentiveness] important [in your daily life]?'

JS3: ' 'around 70\%'

I: 'well then, why's that?'

JS3: 'um, of cour-, people who are the recipients of attentiveness are of course, um, pleased I think, and the persons who are being attentive don't feel badly I think.

But, um, when it goes too far it becomes meddling, so it’s minus 30\%'

The student suggests that the person being attentive may not feel badly, and so may feel pleased or satisfied by demonstrating attentiveness, and the beneficiary may also feel pleased by receiving attentiveness most of the time. There are, however, cases, according to the student, where people go too far. In such cases, attentiveness is evaluated as "meddling", from which it can be inferred that being excessively attentive is not always necessary. ${ }^{9}$

The Taiwanese participants also reported that empathy can be evaluated negatively by others. In responding to whether she thinks being empathic is important in daily life, one of the students claimed that it needs to be pitched at an "appropriate" (shìdàng) level.

(4) TS9

I: 好, 那你覺得在日常生活當中對人家體貼是重要的嗎?

TS9: 要適當吧!因為有時候其實過度的體貼會造成別人的困擾

I: 恩

TS9：＼cjkstart就譬如說,我不需要我明明就不需要而且你說不定不了解我在想什麼或者 是你根本不懂那你的體貼對我來說只是一種困擾

I: 'Do you think it is important to practice empathy (tititie ) with others in daily life?'

TS9: ' '[It] needs to be appropriate, because sometimes excessive empathy will create hassles for people'

I: 'mm'

TS9: 'For example, if I don’t need [your empathy], then just let it be. Probably, you don’t really know what I am thinking. Then your empathy towards me, it’s just a hassle’

Here the student claims that when the empathy is excessive or unwanted it becomes "troublesome" or a "hassle" (kùnrăo) for the recipient of that empathy. One reason for the occurrence of this kind of excessive or unwanted empathy is suggested by the participant to be that the person practicing empathy doesn't fully understand the recipient's situation or mindset.

\footnotetext{
${ }^{9}$ The same perception was said to hold for practicing empathy by the same participant (data not shown), which indicates that the participants did not necessarily clearly distinguish between the three concepts, as noted in footnote 8 .
} 
In the case of both Japanese and Taiwanese, then, attentiveness and empathy can be evaluated negatively as "meddling". The Taiwanese participants went further, however, in suggesting that it can also be seen as creating "hassle" in some instances. And one Taiwanese parent went so far as to characterize attentiveness as "calculating” (bìzhà), in the sense that it is masking some underlying agenda on the part of the one who is (ostensibly) showing attentiveness or empathy. Indeed, the way in which empathy and attentiveness can be evaluated negatively on occasion was something that was emphasized more strongly by the Taiwanese participants. This can be regarded as a key difference between the Japanese and Taiwanese participants' understandings of attentiveness, as the Japanese participants did not make any reference to these kinds of negative feelings in our data.

The emphasis on the possible negative effects of attentiveness and empathy among Taiwanese participants can be traced, in part, to the way in which practicing empathy is said to create "emotional debts” (rénqíngzhài) in ongoing relationships, if such demonstrations of empathy cannot be reciprocated. One of the Taiwanese parents, for instance, mentioned such debts when responding to a question from the interviewer about whether she has experienced empathy from others.

(5) TP6

TP6: 好像我幫別人的時候，不覺得人家會欠我一份人情，我會覺得說好像我自己 主動要去做的; 可是換一個角度的時候、換我的時候, 我會覺得說, 我會 不好意思，然後覺得說，讓你幫了，我會覺得說…就算一點點小忙，我會 覺得在心底欠你一份人情、欠很久，會覺得有時候找個機會把這個情還掉。 所以說, 到最後有一些狀況變成說, 遇到的時候, 我真的沒有那個能力的 時候，我會覺得說…我有時候會覺得很內疚，我沒有辦法幫你。

TP6: It seems when I help others, I don’t think people will owe me emotion (rénqíng) I would feel I am doing it voluntarily; however, take from another perspective, when it is my turn [to get help from others], I would feel embarrassed (bùhăoyisu) Then I would feel, [after] getting the help from you, I feel......although it's only a small matter, I feel I owe you emotion (rénqíng) and [I would feel I] owe you a long time. I feel I sometimes I will find an opportunity to pay this emotivity (rénqíng) back. Therefore, in the end, there are some situations which become... when there is a chance and I have no ability [to help], I would feel....I sometimes feel very guilty that I can't help you'

In this excerpt, the participant talks about her feeling that she remains indebted "emotionally" when others show empathy towards her, as this creates relational entitlements that they may exercise in the future (Chang and Haugh 2011a: 2953; Chang forthcoming). Somewhat paradoxically, however, she also claims that she does not necessarily expect others to reciprocate empathy when she has shown it towards them. These emotional debts are claimed by this participant to create a sense of "embarrassment" and "unease" (bùhăoyisu) (Chang and Haugh 2011b: 432), and even a sense of "guilt” (nèijiù) on her part when she feels she is not able to reciprocate this concern or care.

In contrast to the potential negative feelings that being attentive can occasion among the Taiwanese, the Japanese participants regarded being seen as attentive as an important self-presentational concern (i.e. what Fukushima [2011: 550] terms “reflexive attentiveness”). Some Japanese students, in particular, reported that being seen as attentive can enhance one's reputation, and may also mean that one may benefit from attentiveness from others in the future. One of the Japanese students, for example, when asked whether showing attentiveness is important in daily life, responded that it is important and then went on to justify her response as follows:

(6) JS9

JS9: 少しでも気配りができれば、相手も、相手にも好印象を与えられるし、

結構. . . 何ですか叔．．好印象も与えられるし、もし自分が

頼みたい時も、そうやって前にやっとくとあの一、相手もこう、

また気配りを返し．．気配りをしてくれるように、なることが

多かったので、大事だと思います。 
JS9: 'if [one] can just demonstrate a little attentiveness (kikubari), the other person will also, one can make a good impression with others, to a large extent ... what [to say]...[one] can make a good impression, and if one wants something sometime, if one does that way, in the end, others will also return the attentiveness (kikubari) [in this way]...there were many cases where I have received attentiveness (kikubari), and so it is important I think'

Here the student claims that attentiveness is important for creating a good impression of oneself with others, and also because the recipients of one's attentiveness may reciprocate this in the future.

Another point of difference was that while Japanese participants considered "making allowances for others" to be a form of empathy, this was not identified as a form of empathy by any of the Taiwanese participants. What was meant by "making allowances" is illustrated by the following excerpt from an interview with one of the Japanese students who is recalling her time as a junior and senior high school student with her brothers.

(7) JS7

JS7:

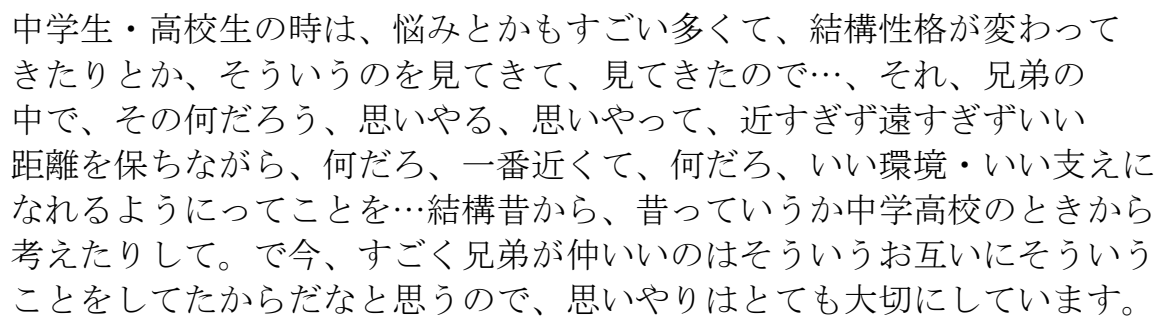

JS7: 'When [we] were junior and senior high school students, we really had a lot of problems/worries, and our personalities changed a lot, and I saw that kind of thing so... and among my brothers I empathized (omoiyatte) that it was probably that, and so while trying to maintain an appropriate amount of space, neither too close nor too distant, what [can I say], the best, uh, I [tried] to offer good support, a good environment...from way before, from before when we were in junior and senior high school I have been considering this. And now, I get on really well with my brothers, and I think we do this kind of thing mutually, so I'm treating empathy (omoiyari) as very important'

What is implied here by the Japanese student is that even when her brothers were being difficult as they dealt with various problems as teenagers, she nonetheless tried to make allowances for that and maintained support for them, while also being careful to give them space.

We have focused in this cross-cultural analysis on commonalities as well as differences in understandings of attentiveness, empathy and anticipatory inference that emerged between the Japanese and Taiwanese participants. The similarities and differences we have identified here as being potentially "cultural" have been those understandings and orientations that the participants from both the younger and older groups treated as salient. There was also, however, some variability in the understandings and concerns of the younger and older participants in relation to these notions, and thus potentially some degree of intracultural variability also at play. The emphasis on self-presentational concerns was only oriented to by the younger generation of the Japanese participants, for instance. It is possible that this represented a cross-generational difference, and so potentially at least, systematic intracultural variability among speakers of Japanese in relation to their understandings and practice of attentiveness and empathy. However, while the older generation of Japanese participants did not mention self-presentational concerns in their interviews, it would be premature, we believe, to conclude that self-presentational concerns are restricted to younger Japanese. Investigating potential cross-generational differences in emic understandings of notions such as attentiveness, empathy and anticipatory inference is inevitably plagued by the possibility of "false negatives" (i.e. informants not mentioning something that is nevertheless 
important to them). ${ }^{10}$ In the following section, we thus propose that conclusions about possible cross-generational differences are on potentially firmer grounder when they can be observed to arise across different cultural groups, and so are grounded in more than two loci of understanding.

\subsection{Cross-generational-cross-cultural comparison}

There were two key contrasts in understandings of attentiveness, empathy and anticipatory inference that were found between the younger and older generations of the Japanese and Taiwanese participants (i.e. a cross-generational-cross-cultural difference). The first key contrast was that the younger Japanese and Taiwanese both restricted the targets of attentiveness, empathy and anticipatory inference, in ways that were not endorsed, or were even contradicted, by the older generation of Japanese and Taiwanese participants, respectively.

Some Japanese students, for example, reported their attentiveness was often directed at their "superiors", and so, for them, an orientation to attentiveness implicitly involves assessments of the "place one stands" (tachiba) relative to the other (Haugh 2005: 47; Haugh and Obana 2011: 156-157). In the following excerpt, for instance, one of the Japanese students explicitly signalled a concern for demonstrating attentiveness when she is together with others who are of "higher status" (meue) or have a different "place" or "role" (tachiba), when she was asked whether she practices anticipatory inference.

(8) JS4

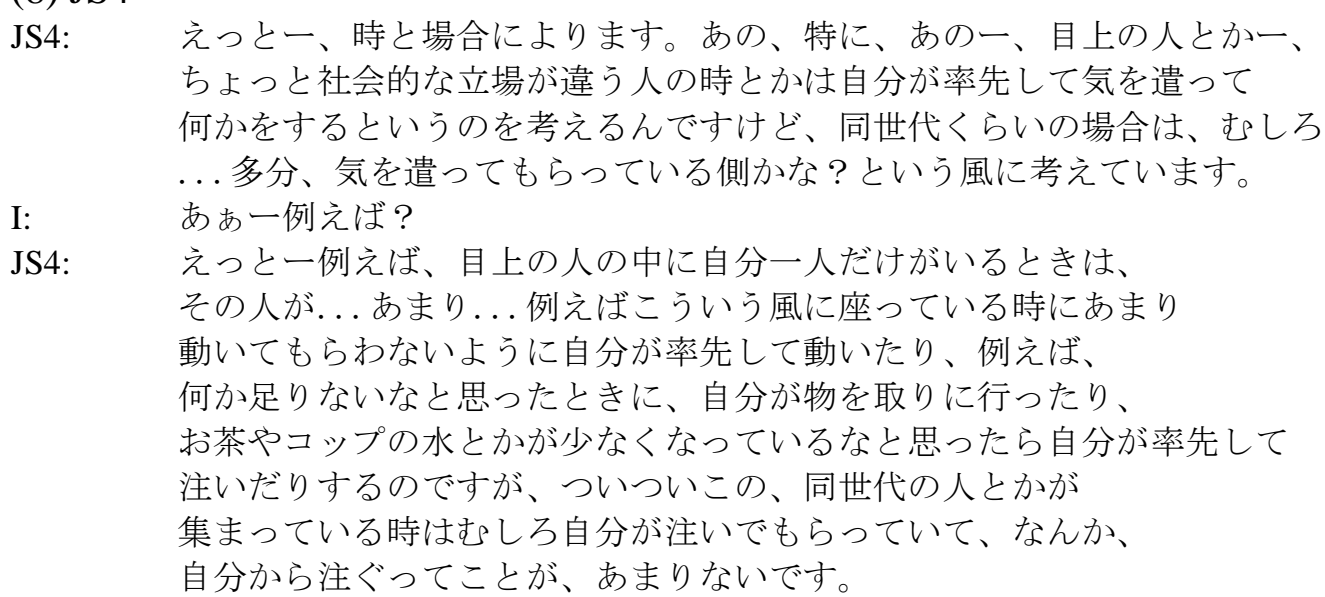

JS4: ' ' $\quad$ um, it depends on the time and situation. Um, sometimes, um, when [I'm] with superiors or those with a social place/role that is different [to mine], I show initiative in paying attention to [their] feelings, and think about what I can do. But in the case of those who are about the same generation [as me], instead, probably, I wonder if [I'm the one who] receives attentiveness (kikubari) I think that way.

I: $\quad$ 'oh for example?'

JS4: 'um, for example, when I'm the only one present among others who are superiors/higher status, that person...not very...for example if we're sitting in a way such that the others [i.e. superiors] don't really have to move, I take the initiative and move, and for example, when I think there's not enough of something, I will go and fetch some more, and if I think the tea or cups of water have lessened, I will take the initiative and pour some. But when I'm gathered together with people of the same generation, I unintentionally end up [letting] others pour, and there are few times when I pour or whatever'

There are two interesting claims made by this participant in regard to when she is attentive to the needs or feelings of others. The first is that she claims to be very attentive, anticipating the needs of people who are

\footnotetext{
${ }^{10}$ Indeed a cross-cultural comparison is potentially dogged by the same problem although in our analysis this problem is arguably ameliorated to some extent by the way in which we have drawn on views from different generations of speakers, and so our cross-cultural findings are grounded not in two but four loci of emic understandings.
} 
socially superior or occupy a different social place or role to her (Haugh 2005: 47), particularly when she is the only "junior" (meshita) present. She gives examples such as taking the initiative to move around, pouring tea, water and other things when it looks like they are going to run out. The second claim is that when she is together with people of a similar age, she is not attentive at all, and indeed is often the recipient of attentiveness. From these two claims, then, we can infer that the participant associates anticipatory inference with (vertical) social status, and that when one is with people of the same generation, being attentive is not necessarily expected by one's peers. In contrast, while the older Japanese associated attentiveness, empathy and anticipatory inference with the place of others, there was no orientation to the possibility of differentially attending only to the feelings or needs of those who are of higher status of socially superior. Given this kind of illustration of attentiveness was not found in the data of the older Japanese, this appears to be a possible cross-generational difference.

The younger Taiwanese also reported that they consider empathy to be something that should be differentially targeted depending on one's relationship with the person in question. A number of Taiwanese students explicitly claimed that they would practice empathy only with close friends or family members and not with strangers. In the following excerpt, the student is responding to being asked whether she often practices empathy with others:

(9) TS10

I: 恩好那你時常會體貼別人嗎?

TS10：＼cjkstart體貼恩恩就是因為我的體貼對大家應該只有家人跟好朋友而已除非 你是我好朋友否則基本上應該是感受不到我的體貼

I: $\quad$ 'mm, then do you often empathize others?

TS10: 'empathy, mm because I only practice empathy (tǐtiē) with my family and good friends. Unless you are my good friend, otherwise, basically [you] can’t feel my empathy (tĭtiēe'

Here the student claims one's empathy for others can only be felt by those who are close, and so implies that she doesn't practice empathy with strangers or people she is not close with. In this way, the participant implicitly invokes the insider-outsider (zìjurén-wàirén) relational distinction (e.g. Chang forthcoming; Gao and Ting-Toomey 1998; Pan 2000; Ye 2004). The exclusion of strangers or people one is not close with as targets of empathy was also reiterated by another Taiwanese student, who had been talking about how she practices empathy with her friends prior to this:

\section{(10) TS16}

$\begin{array}{ll}\text { I: } & \text { 那如果是生活上就是一般生活譬如說你在外面妳看到一般人或者是 } \\ \text { TS16: 恩 } & \\ \text { I: } & \text { 甚至是陌生人這樣的情況妳覺得有辦法做到這樣子嗎? } \\ \text { TS16: } & \text { 我比較不會去理會耶 }\end{array}$

I: $\quad$ 'then if it's in daily life, that is, in your daily life, for example, when you are out and you see normal people or...'

TS16: 'mm'

I: $\quad$ 'even it’s between strangers, do you think you can do it [empathy (tĭtie) ]?'

TS16: I wouldn’t care much’

In this excerpt, the student claims she wouldn't practice empathy with strangers or people she bumps into others in daily life. In doing so, she also implicitly orients to empathy as something that is reserved for “insiders" (ziǰrrén), and that "outsiders" (wàirén) are excluded. Being empathic thus necessarily involves assessments of the relationship that holds between the interactants in question. The stance that outsiders are not legitimate or necessary targets of empathy was explicitly contradicted, however, by participants from the older generation of Taiwanese who mentioned being practicing anticipatory inference, and thus being attentive to the needs or feelings of strangers (who are considered “outsiders" in normal circumstances).

The second key cross-generational contrast, which was found to hold across both the Japanese and Taiwanese participants, was that both the older Japanese and Taiwanese bemoaned the way in which 
attentiveness and empathy is practiced less by younger Japanese and Taiwanese, thereby invoking a discourse of cross-generational gap in their respective understandings of these notions (Marui et al. 1996: 398), or even an alleged "collapse" in the importance placed on them (Kaganoi 1993: 3). One of the Japanese from the older generation, for instance, claimed that people nowadays are not as attentive as they used to be when she was young in accounting for her assertion that attentiveness is not practiced as much by other Japanese because people avoid getting involved with others too intensely.

Kaganoi (1993: 3), for instance, has argued that "tacit understanding" (anmoku no ryoukai) or "consideration for others" (tanin e no hairyo), which underpin the so-called "culture of inference" (sasshi no bunka), are "collapsing" in Japanese culture. While we did not find evidence in the participants' comments that there is the belief that this culture of inference is collapsing per se, there was evidence that it is believed by some older Japanese that the practice of it is decreasing, thereby alluding to discourses of societal and moral change.

(11) JP4

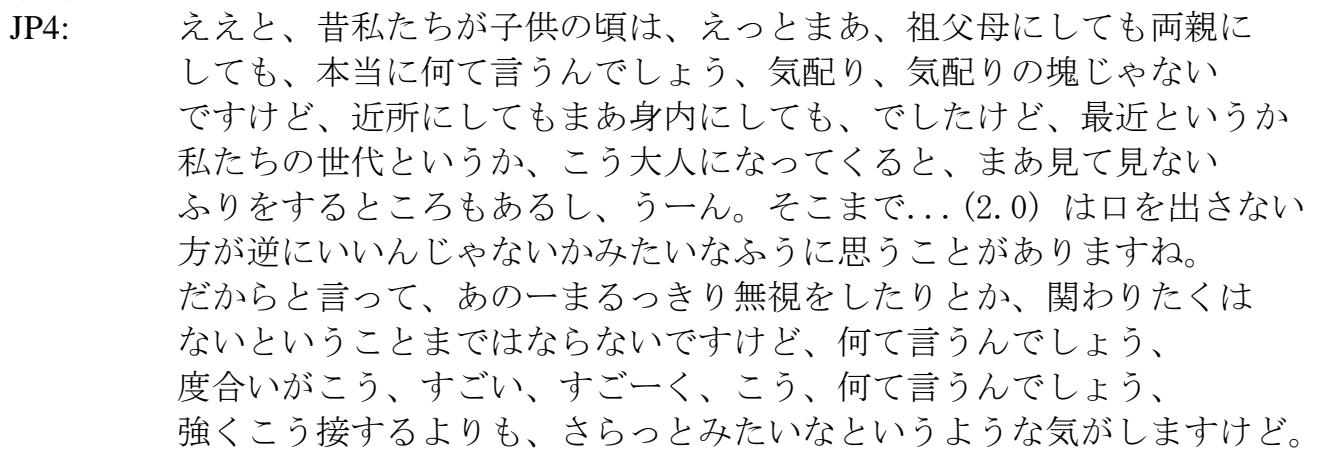

JP4: ' ' um, when we were children, a long time ago, um our grandparents and our parents, were what can I say, attentive, totally attentive, and our neighbors and relatives were also very attentive (kigakiku). However, recently, our generation, upon entering adulthood, well, we can see cases where people pretend to see or not see, yeah. To that extent...((2 sec pause)) I think there are cases where it is better not to say anything. But that does not mean that we are neglecting those around us or that we do not want to get involved [with others], but, what can I say, the degree, very, very, what can I say, I feel that [people] don't connect as strongly with others, but we deal with people lightly’

In this excerpt, the participant claims that the degree to which people are attentive towards each other is much less than it was when she was a child. She claims that the difference between her age group and her parents' or grandparents' age group is a matter of the degree of attentiveness (i.e. to what extent one should be attentive). The former (i.e. younger) age group is argued to be less attentive than the latter (i.e. older), although she does not claim that the younger generation do not want to be attentive per se, but rather that they do not want to be seen as imposing on others. While there are other potentially interesting signs of intracultural variability being alluded to here, what was most interesting, from a cross-cultural perspective at least, was that this kind of discourse was also evident in responses of the older Taiwanese participants.

One of the older Taiwanese participants, for instance, claimed that younger people are not able to practice attentiveness to the same extent as older Taiwanese (including, presumably, herself), when asked whether she considers attentiveness to be important in Taiwanese society.

(12) TP2

TP2: 平常不是說有的年輕人經驗比較不足, 就比較沒辦法看那麼多、

去顧到那麼多面，對不對? 所以我就覺得說，經驗比較... 就是社會經驗、

不管什麼經驗、他都比較成熟的人或是什麼的人、就是...他就會比較周到。

TP2: 'Normally [people] say that the young people have insufficient experience, so they are not able to foresee or deal with so many perspectives, is that right? So I think, the experience, is the social experience...no matter what experience... a more mature or someone [like this] can be more attentive (zhōudào)' 
In this instance, the older participant is claiming that the younger Taiwanese are not able to be as attentive due to a lack of experience, and the inability to infer or anticipate the different perspectives of others.

While there are similarities, one difference in the discourse of participants from the older generation in relation to the decrease in the extent to which attentiveness is practiced among the younger generation, then, was that the Japanese participants claimed younger generations are less frequently attentive compared to the former generations, while the Taiwanese participants claimed the younger generations are less able to be attentive. The latter stance leaves upon the possibility that as the younger generation get older and gain more experience, they may practice attentiveness more. It is thus evident that while the discourses of the older Japanese and Taiwanese in relation to the practice of attentiveness by the younger Japanese and Taiwanese, respectively, is one that is critical of the younger generation, they offer different accounts for this perceived decrease in the practice of attentiveness.

\section{Conclusion}

In this paper, we have undertaken a cross-cultural comparison of emic understandings of three inter-linked notions, that is, attentiveness, empathy, and anticipatory inference, in Japanese and Chinese. Both similarities and differences emerged. One of the similarities was that both the Japanese and Taiwanese participants evaluated attentiveness, empathy and anticipatory inference positively, and so they have the potential to be treated as a "politeness" concern. In other words, the demonstration of attentiveness or showing empathy, after anticipating the other party's needs, wants or feelings, may be evaluated as polite at least in some cases (e.g., Fukushima 2004, 2009, 2011, 2013b; Haugh 2007a, 2014).

The flipside, of course, is that one can be evaluated negatively as "meddling" by demonstrating attentiveness or showing empathy after anticipating the other party's needs, etc. in other instances, which can, in some cases, also be treated as an "impoliteness" concern, as we have seen in our metapragmatic analysis. Both the Japanese and Taiwanese participants reported that demonstrations of attentiveness or showing empathy can be perceived as meddling, although there were some different nuances between these two different cultural groups. In particular, the Taiwanese participants evaluated empathy or attentiveness as "calculating", that is, as disguising a self-interested agenda on the part of the one ostensibly showing empathy. In addition, the Taiwanese participants indicated that empathy can create emotional debts, and thus that it needs to be reciprocated, at least in the context of ongoing relationships, or otherwise it may lead to embarrassment or even feelings of guilt. Another difference between these two cultural groups was the positive evaluation on the part of the Japanese participants that demonstrations of attentiveness may be reciprocated by others in the future. In addition, the Japanese participants also envisaged empathy and attentiveness as involving making allowances for others, which was not found in the Taiwanese data.

In the course of our analysis of these emic understandings we also touched upon potential cross-generational variability. However, given the relatively small number of participants, we elected to only discuss those generational differences that we found in common across both the Japanese and Taiwanese participants. The first key cross-generational difference appeared to be that while younger Japanese and Taiwanese emphasized that attentiveness and empathy was something that needed to be directed at certain persons (those of higher status in the case of younger Japanese, those are relational "insiders" in the case of younger Taiwanese), older Japanese and Taiwanese did not hold the same stance. The second key cross-generational difference to emerge was that the younger generation are not as attentive as those in the past, which was found in common across both older Japanese and Taiwanese. Our metapragmatic analysis thus indicates that there may be significant intracultural variability in understandings of these notions that is deserving of further investigation.

However, we would also like to note that this kind of metapragmatic analysis only gets us so far when considering the possible relevance of such notions to evaluations of im/politeness, as Dunn (2013: 229) points out. Indeed, it needs to be complemented by, and inform, analyses of the practice of attentiveness, empathy and anticipatory inference in actual interactions (see, for instance, Haugh 2007a, 2014). It is also critical to bear in mind that attitudes towards - and the practice of - attentiveness, empathy, and anticipatory inference are not necessarily static over time, or across members who identify themselves as belonging to the same cultural group (Kádár and Haugh 2013: 67), a point which we have touched upon in our analysis of cross-generational-cross-cultural differences. 
We would like to conclude by emphasizing that while we have focused here on emic understandings in Japanese and Chinese, we are not taking the position that these are somehow unique to these languages or cultures. Indeed, we can observe analogous practices in Greek (Sifianou 1992; Sifianou and Tzanne 2010) and English (Fukushima 2009; 2011; Haugh 2014), for instance. However, we would contend that it is only through close metapragmatic analyses of the emic understandings of members, such as that which we have attempted here, that we will have recourse as analysts to a deeper understanding of the moral grounds for evaluations of (im)politeness by participants in interaction. In other words, this kind of metapragmatic analysis arguably affords us a deeper appreciation of the importance of cultural nuances in understandings and evaluations of im/politeness1.

\section{References}

Bousfield, Derek. 2008. Impoliteness in Interaction. Amsterdam: John Benjamins.

Brown, Penelope and Levinson, Stephen C. 1987. Politeness: Some Universals in Language Use. Cambridge: Cambridge University Press.

Burdelski, Matthew. 2013. “I’m sorry, flower”: Socializing apology, relationships, and empathy in Japan. Pragmatics and Society 4 (1): 54-81.

Burdelski, Matthew and Mitsuhashi, Koji. 2010. "She thinks you're kawaii”: Socializing affect, gender and relationships in a Japanese preschool. Language in Society 39: 65-93.

Chang, Wei-Lin Melody. forthcoming. Face and Face Practices in Chinese: An Empirical Analysis of Business Interactions in Taiwan. London: Equinox.

Chang, Wei-Lin Melody and Haugh, Michael. 2011a. Strategic embarrassment and face threatening in business interactions. Journal of Pragmatics 43 (12): 2948-2963.

Chang, Wei-Lin Melody and Haugh, Michael. 2011b. Evaluations of im/politeness of an intercultural apology. Intercultural Pragmatics 8 (3): 411-442.

Clancy, Patricia. 1986. The acquisition of communicative style in Japanese. In Schieffelin, Bambi and Ochs, Elinor (eds.), Language Socialization Across Cultures. Cambridge: Cambridge University Press, pp. 213-250.

Dunn, Cynthia Dickel. 2013. Speaking politely, kindly, and beautifully: Ideologies of politeness in Japanese business etiquette training. Multilingua 32 (2): 225-245.

Eelen, Gino. 2001. A Critique of Politeness Theories. Manchester: St. Jerome.

Fukushima, Saeko. 2000. Requests and Culture: Politeness in British English and Japanese. Bern: Peter Lang.

Fukushima, Saeko. 2004. Evaluation of politeness: The case of attentiveness. Multilingua 23 (4): 365-387.

Fukushima, Saeko. 2009. Evaluation of politeness: Do the Japanese evaluate attentiveness more positively than the British? Pragmatics 19 (4): 501-518.

Fukushima, Saeko. 2011. A cross-generational and cross-cultural study on demonstration of attentiveness. Pragmatics 21 (4): 549-571.

Fukushima, Saeko. 2013a. An attentiveness perspective in metapragmatics of im/politeness. The Tsuru University Graduate School Review 17: 19-34.

Fukushima, Saeko. 2013b. Evaluation of (im)politeness: A comparative study among Japanese students, Japanese parents and American students on evaluation of attentiveness. Pragmatics 23 (2): 275-299.

Gao, Ge and Ting-Toomey, Stella. 1998. Communicating Effectively with the Chinese. Thousand Oaks, CA: Sage.

Garfinkel, Harold. 1967. Studies in Ethnomethodology. Englewood Cliffs, NJ: Prentice-Hall.

Gladkova, Anna. 2010. Sympathy, compassion, and empathy in English and Russian: A linguistic and cultural analysis. Culture and Psychology 16 (2): 267-285.

Gu, Yueguo. 1990. Politeness phenomena in modern Chinese. Journal of Pragmatics 14: 237-257.

Hamano, Kiyoshi. 1987. Ki: A key concept for Japanese interpersonal relations. Psychologia: An international journal of psychology in the Orient 30(2): 101-112.

Hara, Kazuya. 2006. The concept of omoiyari (altruistic sensitivity) in Japanese relational communication. Intercultural Communication Studies 15 (1): 24-32.

Haugh, Michael. 2004. Revisiting the conceptualisation of politeness in English and Japanese. Multilingua 23:85-109. 
Haugh, Michael. 2005. The importance of 'place' in Japanese politeness: Implications for cross-cultural and intercultural analyses. Intercultural Pragmatics 2: 41-68.

Haugh, Michael. 2007a. The co-constitution of politeness implicature in conversation. Journal of Pragmatics 39: 84-110.

Haugh, Michael. 2007b. Emic conceptulisations of (im)politeness and face in Japanese: implications for the discursive negotiation of second language learner identities. Journal of Pragmatics 39: 657-680.

Haugh, Michael. 2007c. The discursive challenge to politeness research: An interactional alternative. Journal of Politeness Research 3: 295-317.

Haugh, Michael. 2010a. The metapragmatics of im/politeness. Plenary talk presented at the $5^{\text {th }}$ International Symposium on Politeness. University of Basel. 30 June, 2010.

Haugh, Michael. 2010b. Intercultural (im)politeness and the micro-macro issue. In Trosborg, Anna (ed.), Pragmatics across Languages and Cultures. Berlin: Mouton de Gruyter, pp. 139-166.

Haugh, Michael. 2013a. Disentangling face, facework and im/politeness. Sociocultural Pragmatics 1: 46-73.

Haugh, Michael. 2013b. Im/politeness, social practice and the participation order. Journal of Pragmatics 58: 52-72.

Haugh, Michael. 2013c. Inference and implicature. In Chapelle, Carol A. (ed.), The Encyclopedia of Applied Linguistics. Oxford: Wiley-Blackwell, pp.2658-2665.

Haugh, Michael. 2014. (Im)politeness Implicatures. Berlin: Mouton de Gruyter.

Haugh, Michael and Obana, Yasuko. 2011. Politeness in Japan. In Kádár, Daniel and Mills, Sara (eds.), Politeness in East Asia. Cambridge: Cambridge University Press, pp. 147-175.

Ide, Sachiko. 1989. Formal forms and discernment: Two neglected aspects of universals of linguistic politeness. Multilingua 8 (2/3): 223-248.

Ide, Sachiko, Hill, Beverly, Carnes, Yukiko M., Ogino, Tsunao and Kawasaki, Akiko. 1992. The concept of politeness: An empirical study of American English and Japanese. In Watts, Richard J., Ide, Sachiko, and Ehlich, Richard (eds.), Politeness in Language: Studies in its History, Theory and Practice. Berlin: Mouton de Gruyter. pp. 299-323.

Intachakra, Songthama. 2012. Politeness motivated by the 'heart' and 'binary rationality' in Thai culture. Journal of Pragmatics 44: 619-635.

Ishii, Satoshi. 1984. Enryo-sasshi communication: a key to understanding Japanese interpersonal relations. Cross Currents 11:49-58.

Kádár, Dániel and Haugh, Michael. 2013. Understanding Politeness. Cambridge: Cambridge University Press.

Kaganoi, Shuichi. 1999. Nihonjin, sono 46: Katariau bunka o souzoushi, “amayakasareta” Nihongo o kitaenaosu koto ga motomerareu [It is needed to create a culture to "talk together" and train “spoiled” Japanese language again]. On the Line 4:12-13.

Krippendorff, Klaus. 2013. Content Analysis. An Introduction to its Methodology ( $3^{\text {rd }}$ edn). London: Sage.

Lebra, Takie Sugiyama. 1976. Japanese Patterns of Behavior. Honolulu: University of Hawaii Press.

Lebra, Takie Sugiyama. 2004. The Japanese Self in Cultural Logic. Honolulu: University of Hawai'i Press.

Locher, Miriam and Watts, Richard. 2005. Politeness theory and relational work. Journal of Politeness Research 1: 9-34.

Mao, LuMing Robert. 1994. Beyond politeness theory: 'Face’ revisited and renewed. Journal of Pragmatics 21: 451-486.

Matsumoto, Yoshiko. 1998. Politeness and conversational universals - observations from Japanese. Multilingua 8 (2/3): 207-221.

Marui, Ichiro, Nishijima, Yoshinori, Noro, Kayoko, Reinelt, Rudolf and Yamashita, Hiroshi. 1996. Concepts of communicative virtues (CCV) in Japanese and German. In Helinger, Marlis and Amman, Ulrich (eds.), Contrastive Sociolinguistics. Berlin: Mouton de Gruyter, pp. 385-409.

Miike, Yoshitaka. 2003. Japanese enryo-sasshi communication and the psychology of amae: reconsideration and reconceptualization. Keio Communication Review 25: 93-115.

Mills, Sara. 2003. Gender and Politeness. Cambridge: Cambridge University Press. 
Miyake, Kazuko. 2011. Nihongo no Taijinkankei Haaku to Hairyo Gengokoudou [A proper understanding of personal relationships in Japanese and linguistic behavior of consideration]. Tokyo: Hituzi Syobo.

Obana, Yasuko and Tomoda, Takako. 1994. The sociological significance of "politeness" in English and Japanese languages. Report from a pilot study. Japanese Studies Bulletin 14 (2): 37-49.

Ohashi, Jun. 2013. Thanking and Politeness in Interaction: Balancing Acts in Interaction. Basingstoke, UK: Palgrave Macmillan.

Okabe, Roichi. 1983. Cultural assumptions of East and West. In Gudykunst, William (ed.), Intercultural Communication Theory. Current Perspectives. London: Sage, pp. 21-44.

Pan, Yuling. 2000. Politeness in Chinese Face-to-Face interaction. Stanford, CA: Ablex.

Pan, Yuling and Kádár, Dániel Z. 2011. Politeness in Historical and Contemporary Chinese. London: Continuum.

Pizziconi, Barbara. 2007. The lexical mapping of politeness in British English and Japanese. Journal of Politeness Research 3 (2): 207-241.

Potter, Jonathan, and Hepburn, Alexa. 2005. Qualitative interviews in psychology: problems and possibilities. Qualitative Research in Psychology 2: 281-307.

Pudlinski, Christopher. 2005. Doing empathy and sympathy: caring responses to troubles tellings on a peer support line. Discourse Studies 7 (3): 267-288.

Shinmura, Izuru (ed.). 2008. Kojien (6 ${ }^{\text {th }}$ edition). Tokyo: Iwanami shoten.

Sifianou, Maria. 1992. Politeness Phenomena in England and Greece: A Cross-Cultural Perspective. Oxford: Clarendon.

Sifianou, Maria and Tzanne, Angeliki. 2010. Conceptualizations of politeness and impoliteness in Greek. Intercultural Pragmatics 7 (4): 661-687.

Spencer-Oatey, Helen. 2000. Rapport management: A framework for analysis. In Spencer-Oatey, Helen (ed.), Culturally Speaking: Managing Rapport through Talk across Cultures. London: Continuum, pp. 11-46.

Spencer-Oatey, Helen. 2002. Managing rapport in talk: Using rapport sensitive incidents to explore the motivational concerns underlying the management of relations. Journal of Pragmatics 34 (5): 529-545.

Spencer-Oatey, Helen. 2005. (Im)Politeness, face and perceptions of rapport: unpackaging their bases and interrelationships. Journal of Politeness Research 1: 95-120.

Takada, Akira. 2013. Generating morality in directive sequences: Distinctive strategies for developing communicative competence in Japanese caregiver-child interactions. Language \& Communication 33: 420-438.

Terkourafi, Marina. 2011. From politeness1 to politeness2: Tracking norms of im/politeness across time and space. Journal of Politeness Research 7: 159-185.

Tracy, Karen, and Robles, Jessica. 2010. Challenges of interviewers' institutional positionings: taking account of interview content and interaction. Communication Methods and Measures 4 (3): $177-200$

Travis, Catherine. 1997. Kind, considerate, thoughtful: A semantic analysis. Lexikos 7: 130-152.

Travis, Catherine. 1998. Omoiyari as a core Japanese value: Japanese-style empathy? In Athanasiadou, Angeliki and Tabakowska, Elzbieta (eds.), Speaking of Emotions: Conceptualisation and Expression. Berlin: Mouton de Gruyter, pp. 55-81.

Uchida, Yukiko and Kitayama, Shinobu. 2001. Development and validation of a sympathy scale. The Japanese Journal of Psychology 72 (4): 275-282.

Watanabe, Toshiro, Skrzypczak, Edmund R. and Snowden, Paul (eds.). 2003. Kenkyusha's New Japanese-English Dictionary ( $5^{\text {th }}$ edition). Tokyo: Kenkyusha.

Watts, Richards J. 2003. Politeness. Cambridge: Cambridge University Press.

Wierzbicka, Anna. 1997. Understanding Cultures through their Key Words. Oxford: Oxford University Press.

Yamada, Haru. 1997. Different Games, Different Rules. Oxford: Oxford University Press.

Ye, Zhengdao. 2004. Chinese categorization of interpersonal relationships and the cultural logic of Chinese social interaction: an indigenous perspective. Intercultural Pragmatics 1 (2): 211-230. 